\title{
Mucin Histochemistry in Tumours of Colon, Ovaries and Lung
}

\section{Usman Ali*, Nagi AH, Nadia Naseem and Ehsan Ullah}

Department of Morbid Anatomy and Histopathology, University of Health Sciences, Lahore, Pakistan

\begin{abstract}
Introduction: Mucins implicated in cancers of various organs. The apical epithelial surfaces of mammalian respiratory, gastrointestinal, and reproductive tracts are coated by mucus, a mixture of water, ions, glycoproteins, proteins, and lipids.

The purpose of this study was to confirm the presence of mucin production using Haematoxylin and Eosin (H\&E) stain as the gold standard and to describe the types of mucins produced in tumors of lung, colon and ovaries using various types of histochemical techniques.

Methods: The resection specimens and biopsies from tumours of colon $(n=16)$, ovaries $(n=13)$ and lung ( $n=5)$ were included and stained with H\&E to determin the histological diagnosis for selecting tissues with mucin production. Slides were stained with PAS, Alcian blue, High iron diamine-Alcian blue, Meyer's mucicarmine and Alcian blue-PAS to demonstrate the mucin production and to identify types of mucins.
\end{abstract}

Results: In the present study we observed predominance of acid mucins over neutral mucins. In addition in these cases we observed sulphomucin predominating over sialomucin.

Conclusion: Mucin histochemistry can effectively determine the types of mucins.

Keywords: Haematoxylin and Eosin; Periodic acid schiff; High iron diamine; Alcian blue

\section{Introduction}

Mucin is a high molecular weight glycoprotein that is synthesized, stored and secreted by the epithelial mucosal cells, especially the goblet cells [1]. Mucins are expressed by various epithelial cell types that exist in relatively harsh environments [2] Mucins' key characteristic is its ability to form gels; therefore they are a key component in most gellike secretions, serving functions such as lubrication, cell signaling and forming chemical barriers [3]. Histochemically, the mucins are classified into neutral mucins and acidic mucins which include sulpho and sialo mucins. Many reviews on their histochemical classification and identification have been put forward to explain the intricacies of mucins. The simplest, yet a lucid method to identify mucins by routine light microscopy were employed in the present study [4]. Their general structure and biochemical composition provides protection for the cell surface and specific molecular structures regulate the local microenvironment near the cell surface. In addition, mucins also communicate the information of the external environment to the epithelial cells via cellular signalling through membrane-anchored mucins $[5,6]$. Mucus provides a protective barrier against pathogens and toxins and contributes to the innate defensive system in mucosal immunology [7]. It seems that mucins play a role in the processes of tumour progression, invasion and metastasis and also in tumour cell survival and protection against the host immune response [8]. Increased mucin production occurs in many adenocarcinoma, including cancers of pancreas, lung, breast, ovary, colon and other tissues [9]. Mucinous tumours represent a subgroup of carcinomas exhibiting large amounts of mucus, grossly visible during microscopic examination. This morphological definition applies with some modifications to about 1020 per cent of colonic, 5 per cent of breast, 3 per cent of ovarian, and 1 per cent of pancreatic carcinomas. The colonic mucinous carcinomas are most precisely defined in this group: according to the WHO definition, at least 50 per cent of the microscopically evaluated area in these tumours must be filled with mucus [10].

\section{Materials and Methods}

Paraffin embedded sections were prepared using automatic tissue processor, followed by preparation of paraffin block using our embedding station. The sections were stained with H\&E stain to determine the histological diagnosis for selecting tissues with mucin production. Slides were stained with PAS, Alcian blue, high iron diamine-Alcian blue, Meyer's mucicarmine and Alcian blue-PAS to demonstrate the mucin production. Positive and negative controls were run for quality assurance. Here is a brief account of various mucin stains summarized along with their characteristics. Meyer's mucicarmine [11,12] is most frequently used histochemical stain to demonstrate acidic mucin. These stains are useful in demonstrating both intracellular and extracellular mucins. PAS (peroidic acid-Schiff) stains glycogen as well as mucins, but tissue can be pre-digested with diastase to remove glycogen rendering PAS an important mucin stain [13] The Alcian Blue stain is primarily used to stain acid mucopolysaccharides. The alcian blue stain at a $\mathrm{pH}$ of 2.5 stains for both sulfated (sulphomucins) and carboxylated (sialomucins) mucopolysaccharides which are found in the goblet cells located in the intestine. Alcianblue-PAS staining is used to differentiate between acid and neutral mucins [14]. High iron diamine-Alcian blue detects sulfomucins (brown) and sialomucins in tissue [15].

\section{Results}

We included 34 cases from different organs $i, e$ colon $(n=16)$, ovaries

*Corresponding author: Usman Ali, Department of Morbid Anatomy and Histopathology, University of Health Sciences, Lahore, Pakistan, E-mail: usmanali36877@gmail.com

Received November 30, 2012; Accepted December 29, 2012; Published December 31, 2012

Citation: Ali U, Nagi AH, Naseem N, Ullah E (2012) Mucin Histochemistry in Tumours of Colon, Ovaries and Lung. J Cytol Histol 3: 163. doi:10.4172/21577099.1000163

Copyright: @ 2012 Ali U, et al. This is an open-access article distributed under the terms of the Creative Commons Attribution License, which permits unrestricted use, distribution, and reproduction in any medium, provided the original author and source are credited. 
Citation: Ali U, Nagi AH, Naseem N, Ullah E (2012) Mucin Histochemistry in Tumours of Colon, Ovaries and Lung. J Cytol Histol 3: 163. doi:10.4172/2157-7099.1000163

$(\mathrm{n}=13)$ and lungs $(\mathrm{n}=5)$. They were divided into the following groups on the basis of mucin content in the whole section which was marked from ' + ' to ' +++ 'as follows: mild $(<20 \%)=+$, moderate $(20-40 \%)=++$, marked $(40-60 \%)=+++$. Sections from normal colon were taken as controls. We observed the location of mucins which are extra-cellular or intra-cellular or both extra-cellular and intra-cellular mucins on the basis of $\mathrm{H} \& \mathrm{E}$ staining. We observed that $50 \%$ cases showed both extra-cellular and intra-cellular mucins that was dominant in our study and $38.2 \%$ cases showed extra-cellular mucins and only $11.8 \%$ showed intra-cellular mucins. After H\&E staining we performed PAS stain for mucins. In PAS stain we could locate the mucins better than H\&E staining but in this stain we did not differentiate the types of mucins. In PAS staining we observed that $70.60 \%$ cases showed mild mucin, $17.60 \%$ cases contained moderate mucin and $11.80 \%$ cases showed marked mucin in tissues. All the cases of mucinous adenocarcinoma of lung showed only a mild mucin but in ovary and colon we found different results from mild to marked mucins. After mucicarmine staining we differentiated the acidic mucins but not the other types of mucins. In $61.8 \%$ cases we observed mild mucin, $35.3 \%$ cases showed moderate mucin and $2.9 \%$ cases contained only marked mucin. However, after mucicarmine stain we could not differentiate the types of mucins. In Alcian blue staining 73.5\% cases showed mild mucin, $8.8 \%$ cases showed moderate mucin, $8.8 \%$ cases showed marked mucin and $8.8 \%$ cases showed no mucin. The Alcian blue staining differentiated the acidic mucins from other types of mucins. On the other hand Alcian blue-PAS stain differentiated both neutral and acidic mucins. The Alcian blue-PAS staining showed $67.6 \%$ cases with mild acidic mucin, $20.6 \%$ cases with moderate acidic mucin in $5.9 \%$ cases marked mucin was present and in $2.9 \%$ cases we observed mild neutral mucin and in $2.9 \%$ cases we observed moderate neutral mucins. In High Iron Diamine-Alcian blue staining we could differentiate the sulphomucin in which we observed black brown colour and the sialomucin in which we found shades of blue colour. On the basis of mucin content in High Iron Diamine-Alcian blue staining $50.6 \%$ cases showed mild sulphomucin, $17.6 \%$ cases showed moderate sulphomucin, in $2.9 \%$ cases they showed marked sulphomucin, $5.9 \%$ cases contained mild sialomucin were present, 5.9\% cases showed moderate sialomucin and in $17.6 \%$ cases there were both sulphomucin and sialomucin (Tables 1,2 and Figures 1-7).

\begin{tabular}{|c|c|c|c|c|c|c|}
\hline \multirow{2}{*}{ Tissue organs } & \multicolumn{3}{|c|}{ Acidic mucin } & \multicolumn{3}{c|}{ Neutral mucin } \\
\cline { 2 - 7 } & Mild & Moderate & Marked & Mild & Moderate & Marked \\
\hline Colon & 9 & 6 & 1 & 0 & 0 & 0 \\
\hline Ovary & 10 & 0 & 1 & 1 & 1 & 0 \\
\hline Lung & 4 & 1 & 0 & 0 & 0 & 0 \\
\hline Total & 23 & 7 & 2 & 1 & 1 & 0 \\
\hline Percent\% & $67.6 \%$ & $20.6 \%$ & $5.9 \%$ & $2.9 \%$ & $2.9 \%$ & 0 \\
\hline
\end{tabular}

Mild =+, Moderate $=++$, Marked $=+++$

Table 1: Shows staining results of Alcian blue-PAS in different organs.

\begin{tabular}{|l|c|c|c|c|c|c|c|}
\hline $\begin{array}{l}\text { Tissue } \\
\text { organs }\end{array}$ & \multicolumn{3}{|l|}{ Sulphomucin } & \multicolumn{3}{l|}{ Sialomucin } & \multicolumn{2}{l|}{$\begin{array}{l}\text { Both } \\
\text { (sulphomucin \& } \\
\text { sialomucin) }\end{array}$} \\
\cline { 2 - 9 } & Mild & Moderate & Marked & Mild & Moderate & Marked & \\
\hline Colon & 7 & 2 & 1 & 1 & 2 & 0 & 3 \\
\hline Ovary & 6 & 4 & 0 & 1 & 0 & 0 & 2 \\
\hline Lung & 4 & 0 & 0 & 0 & 0 & 0 & 1 \\
\hline Total & 17 & 6 & 1 & 2 & 2 & 0 & 6 \\
\hline Percent $\%$ & $50.6 \%$ & $17.6 \%$ & $2.9 \%$ & $5.9 \%$ & $5.9 \%$ & 0 & $17.6 \%$ \\
\hline
\end{tabular}

Mild $=+$, Moderate $=++$, Marked $=+++$

Table 2: shows staining results of high Iron Diamine-Alcian blue in different organs.

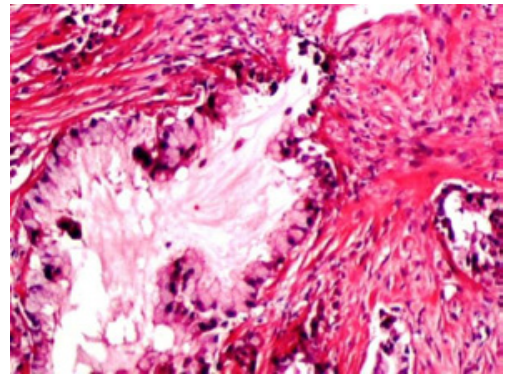

Figure 1: Photomicrograph shows mucin after Haematoxylin \& Eosin stain in mucinousadenocarcinoma of lung.

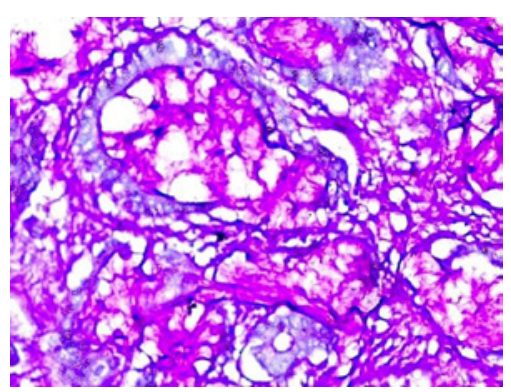

Figure 2: Photomicrograph shows mucin (magenta) after PAS stain in mucinous adenocarcinoma of colon.

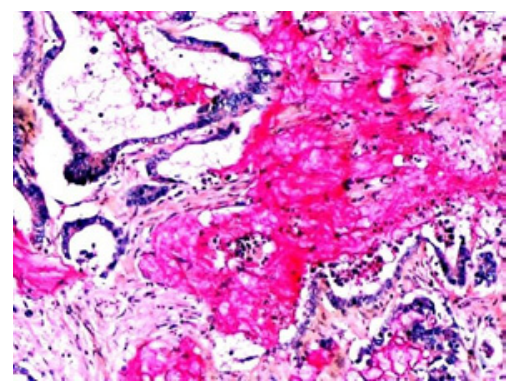

Figure 3: Photomicrograph shows acidic mucin (deep rose) after mucicarmine stain in mucinous adenocarcinoma of colon.

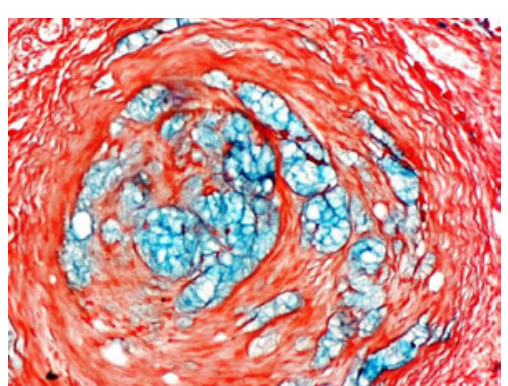

Figure 4: Photomicrograph shows acidic mucin (blue) after alcian blue stain in mucinous adenocarcinoma of colon $\times 60$.

\section{Discussion}

Mucins are complex carbohydrates secreted by epithelial and connective tissue cells. Mucin glycoproteins are thought to play an important role in protecting the intestine from chemical or physical injury but the mechanisms of protection and the possible relationship 
Citation: Ali U, Nagi AH, Naseem N, Ullah E (2012) Mucin Histochemistry in Tumours of Colon, Ovaries and Lung. J Cytol Histol 3: 163. doi:10.4172/2157-7099.1000163

Page 3 of 4

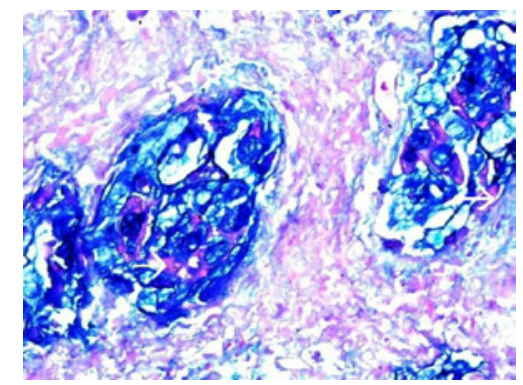

Figure 5: Photomicrograph shows acidic mucin (blue) and arrow shows neutral mucin (magenta) after Alcian blue-PAS stain in an mucinous carcinoma of lung.

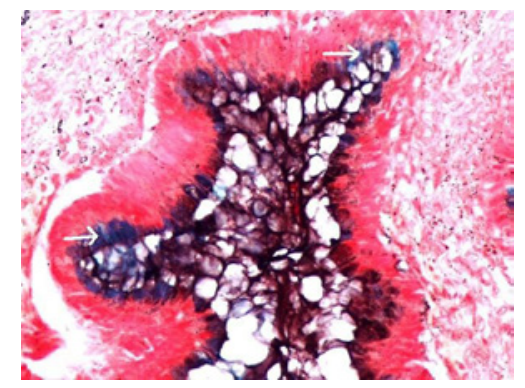

Figure 6: Photomicrograph shows sulphomucin (brown) and arrow shows sialomucin (blue) after HID-Alcian blue stain in mucinous adenocarcinoma of ovary.

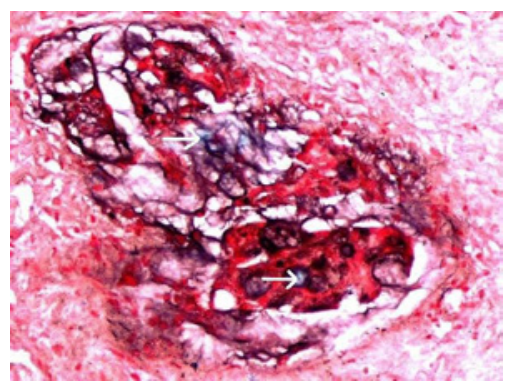

Figure 7: Photomicrograph shows sulphomucin (brown) and arrow shows sialomucin (blue) after HID-Alcianblue stain in mucinous carcinoma of lung.

between mucin structure and function are incompletely understood. Structurally, purified intestinal mucins are a heterogeneous and polydisperse group of large-molecular-weight glycoproteins which have regional and developmental differences in composition. Mucin glycoproteins have been implicated in the pathogenesis of epithelial cell malignancies [16]. Alterations of the expression pattern of mucins have been described in carcinomas as well as in their precursor lesions [17]. Although [18] have shown a worse prognosis for tumours with mucin as compared to tumours with no mucin content, the authors advocate the use of staging as superior to histological grading as a criterion for prognosis. Mucinous adenocarcinomas account for $10-20 \%$ in most Western series $[19,20]$. There may be a difference in this percentage between Western and Asian (4-5\%) populations. Some authors find the mucinous neoplasm occurring more common in males [21] and others find no significant difference [20]. Mucinous carcinoma is a histological variant that accounts for $5 \%$ to $15 \%$ of cases of primary colorectal cancer [22]. Compared with nonmucinous carcinoma, mucinous carcinoma has been known to have a propensity for higher incidence of lymph node metastasis, venous and lymphatic invasions, local recurrence, and distant metastasis. Consequently, the prognosis is worse. Therefore, mucinous carcinomas require more aggressive surgical excision, with wide margins, extensive lymph node dissection, and complete dissection of tumour extending into adjacent structures, than do nonmucinous carcinomas [23]. The incidence of mucinous carcinomas in Europe and the United States is approximately 10\% [24] and that in Japan is low, at $2.9 \%$ to $7.4 \%$ [25]. Most investigators have applied histochemical methods to this problem and in particular the high iron diamine/alcian blue staining technique, which permits the simultaneous recognition of sulfated and non-sulfated sialomucins [26]. Different series define mucinous carcinoma as the presence of at least $50 \%-60 \%$ mucin in the extracellular matrix [27]. In some cases there is an admixture of extracellular and intracellular mucin, the latter resulting in signet ring configuration [27]. Although it is not clearly established some variations exist in the amount of extracellular mucin for the definition of mucinous colorectal carcinoma, which range between $50 \%$ and $80 \%$ [28]. Recent studies however have reported a higher incidence of mucinous adenocarcinoma [27,29]. In the present study the incidence of extracellular mucin and combined extracellular and intracellular mucins are similar to those reported [30]. In some cases there is an admixture of extracellular and intracellular mucin, the latter resulting in signet ring configuration [27]. Recent studies however have reported a higher incidence of mucinous adenocarcinoma [27,29]. The PAS technique is perhaps the most versatile and widely used of the techniques for the demonstration of glycoproteins, carbohydrates and mucins. The PAS technique is particularly sensitive to the detection of neutral mucins as well as acid mucins that contain significant quantities of sialic acid. The combined alcian blue $\mathrm{AB} / \mathrm{PAS}$ technique is widely used for the detection and characterization of mucosubstances in tissue sections. The Alcian blue-PAS technique is a simple procedure and appears to differentiate sharply between acid mucins and neutral mucins. This might be of value in demonstrating small amounts of acid mucin. The acid mucins being the predominant type ( $>90 \%$ of cases) [31]. They noticed that AB/PAS stain revealed the prevalence of acid mucins. The high-iron diamine-alcian blue sequence stains sulfomucins dark brown to black and sialomucins stain blue. Another study revealed that the $\mathrm{HID} / \mathrm{AB}$ stain highlighted the predominance of sialomucins [31] contrary to these we found different results i,e the predominant mucin in our study was sulphomucin followed by both sulphomucin and sialomucin whereas sialomucin was observed only in 4 cases. However the number of cases in our study was rather small [32] found abundant neutral and acidic mucins in approximately equal amounts in ovarian tissue. A slight predominance of sialomucins over sulfomucins was found. In our study we observed predominance of acid mucins over neutral mucins. In addition in these cases we observed sulphomucin predominating over the sialomucin. We also found that in mucinous adenocarcinoma of lung sulphomucins were present and in one case both sulphomucins and sialomucins were detected whereas we could not find any histochemical studies on mucinous adenocarcinoma of lung from literature. It is felt that mucin content is our study was an independent adverse prognostic factor, however other researchers still debate the fact that it is not regarded as an independent prognostic factor. According to Sanjay et al. the current consensus of College of American Pathologists (CAP) and American Joint Committee for Cancer (AJCC) is that mucinous differentiation is not proven to be a statistically significant prognostic factor independent of histological grade [33]. In other studies [34,35] mucinous adenocarcinoma showed a higher tumour grade than non- mucinous adenocarcinoma . 
Citation: Ali U, Nagi AH, Naseem N, Ullah E (2012) Mucin Histochemistry in Tumours of Colon, Ovaries and Lung. J Cytol Histol 3: 163. doi:10.4172/2157-7099.1000163

\section{Conclusion}

Mucin histochemistry can effectively determine the presence and types of mucins. The PAS, mucicarmine and Alcian blue are localizing stains for mucins but could not differentiate the types of mucins. In mucin histochemistry we observed better contrast of alcian blue/PAS for acid and neutral mucins as compared to HID/AB for sulphomucin and sialomucin. In mucinous adenocarcinoma we observed the dominance of acid and sulphomucin.

Mucinous adenocarcinomas need to be further investigated at molecular level to elucidate the biological significance of mucin in carcinoma.

\section{Acknowledgments}

This experiment was supported by University of Health Sciences, Lahore. We are thankful to the pathologists who let us have the tumours tissues of their patients.

\section{References}

1. Kim YS, Gum JR Jr, Byrd JC, Toribara NW (1991) The structure of human intestinal apomucins. Am Rev Respir Dis 144: S10-14.

2. Forstner JF (1978) Intestinal mucins in health and disease. Digestion 17: 234263.

3. Marin F, Luquet G, Marie B, Medakovic D (2008) Molluscan shell proteins: primary structure, origin, and evolution. Curr Top Dev Biol 80: 209-276.

4. Stanley S, Rapheal SS (1997) Staining of Carbohydrates and Connective Tissue around substance: Fibrin and Amyloid. In: Lynch Medical Laboratory Technology, (3rdedn). Philadelphia; W.B. Saunders Company: 963-979.

5. Moniaux N, Escande F, Porchet N, Aubert JP, Batra SK (2001) Structural organization and classification of the human mucin genes. Front Biosci 6: D1192-1206.

6. Hollingsworth MA, Swanson BJ (2004) Mucins in cancer: protection and control of the cell surface. Nat Rev Cancer 4: 45-60.

7. Corfield Ap, Shukla AK (2004) Mucins: vital components of the mucosal defensive barrier. Genomic/Proteomic Technol 3: 20-22.

8. Komatsu M, Yee L, Carraway KL (1999) Overexpression of sialomucin complex, a rat homologue of MUC4, inhibits tumor killing by lymphokine-activated killer cells. Cancer Res 59: 2229-2236.

9. Singh AP, Moniaux N, Chauhan SC, Meza JL, Batra SK (2004) Inhibition of MUC4 expression suppresses pancreatic tumor cell growth and metastasis. Cancer Res 64: 622-630.

10. Jass JR, Sobin LH (1990) Histological Typing of Intestinal Tumours, (2ndedn). Berlin: Springer-Verlag.

11. Mayer $P$ (1896) Uber schleimfarbung. Mitteilungen aus der Zoologioschen Station zu Neapal 12: 303.

12. Southgate HW (1927) Note on preparing mucicarmine . Journal of pathology and Bacteriology 30: 729.

13. McMANUS JF (1946) Histological demonstration of mucin after periodic acid. Nature 158: 202

14. Mowry RW (1956) Alcian blue techniques for the histochemical study of acidic carbohydrates. J Histochem Cytochem 4: 407.

15. SPICER SS (1965) Diamine methods for differentialing mucosubstances histochemically. J Histochem Cytochem 13: 211-234.

16. Niv Y (1994) Mucin and colorectal cancer metastasis. Am J Gaslroenterol 89: 665-669.

17. Hakomori S (1989) Aberrant glycosylation in tumors and tumor-associated carbohydrate antigens. Adv Cancer Res 52: 257-331.

18. Hilska M, Collan Y, Roberts PJ, Ovaska J, Kössi J, et al. (2002) Prognostic value of various staging and grading systems in proximal colon cancer. Eur $\mathrm{J}$ Surg 168: 84-90.

19. Consorti F, Lorenzotti A, Midiri G, Di Paola M (2000) Prognostic significance of mucinous carcinoma of colon and rectum: A prospective casecontrol study. $J$ Surg Oncol 73: 70-74.

20. Du W, Mah JT, Lee J, Sankila R, Sankaranarayanan R, et al. (2004) Incidence and survival of mucinous adenocarcinoma of the colorectum: a populationbased study from an Asian country. Dis Colon Rectum 47: 78-85.

21. Thomas RM, Sobin LH (1995) Gastrointestinal cancer. Cancer 75: 154-170.

22. American Joint Committee on Cancer (2002): Staging Manual, (6thedn). New York: Springer.

23. Yamamoto S, Mochizuki H, Hase K (1993) Assessment of clinicopathologic features of colorectal mucinous adenocarcinoma. Am J Surg 166:257-261.

24. Morson BC, Sobin LH (1976) Histological typing of intestinal tumors. Geneva World Health Organization.

25. Maksimović S (2007) [Survival rates of patients with mucinous adenocarcinoma of the colorectum]. Med Arh 61: 26-29.

26. McFadden DE, Owen DA, Reid PE, Jones EA (1985) The histochemical assessment of sulphated and non-sulphated sialomucin in intestinal epithelium. Histopathology 9: 1129-1137

27. Papodopoulos V N, Michalopoulos A, Netta S (2004) Prognostic significance of mucinous component in colorectal carcinoma. Techniques in Colproctology 8: 123-125.

28. Hussain SM, Outwater EK, Siegelman ES (1999) Mucinous versus nonmucinous rectal carcinomas: differentiation with MR imaging. Radiology 213: 79-85

29. Sarli L, Bottarelli L, Azzoni C (2008) Two subtypes of mucinous adenocarcinoma of the colorectum: clinicopathological and genetic features. Ann Surg Onco 15:1429-1439

30. Symonds DA, Vickery AL (1976) Mucinous carcinoma of the colon and rectum Cancer 37: 1891-1900

31. Ionila M, Margaritescu CL, Pirici D, Mogoanta SS (2011). Mucinoous adenocarcinoma of the colon - a histochemical study Rom. J Morphol Embryol 52: 783-790.

32. Rutgers JL, Baergen RN (1994) Mucin histochemistry of ovarian borderline tumors of mucinous and mixed-epithelial types. Mod Pathol 7: 825-828.

33. Kakar S, Aksoy S, Burgart LJ, Smyrk TC (2004) Mucinous carcinoma of the colon: correlation of loss of mismatch repair enzymes with clinicopathologic features and survival. Mod Pathol 17: 696-700.

34. Enríquez JM, Díez M, Tobaruela E, Lozano O, Domínguez P, et al. (1998) Clinical, histopathological, cytogenetic and prognostic differences between mucinous and nonmucinous colorectal adenocarcinomas. Rev Esp Enferm Dig 90: 563-572.

35. Mirna HF, Kassem AB, Ayman NT, Doha MI, Hassan AH, et al. (2008). Effect of mucin production on survival in colorectal carcinoma: A case-controlled study. World J Gastroenterol 14: 6981-6985. 